\title{
Regulation by Machine
}

\author{
Benjamin Alarie \\ Univ. of Toronto, Faculty of Law \\ 78 Queens Park Crescent W. \\ Toronto ON Canada \\ ben.alarie@utoronto.ca
}

\author{
Anthony Niblett \\ Univ. of Toronto, Faculty of Law \\ 78 Queens Park Crescent W. \\ Toronto ON Canada \\ anthony.niblett@utoronto.ca
}

\author{
Albert H. Yoon \\ Univ. of Toronto, Faculty of Law \\ 78 Queens Park Crescent W. \\ Toronto ON Canada \\ albert.yoon@utoronto.ca
}

\begin{abstract}
Legal scholars investigating artificial intelligence are preoccupied with regulation. The literature has largely focused on the need for humans to regulate the behavior of automated systems. In this paper, we focus on the converse: how artificially intelligent systems can serve to regulate human behavior. The shortcomings of human-led regulation are clear. We argue that machine learning technology can address some of these limitations. We provide examples of how machine learning can predict how courts would decide legal disputes more cheaply and accurately than human regulators. This allows regulators to streamline operations, providing fast, accurate, consistent, and reliable ex ante regulatory advice and rulings. We further explore how machine learning technology might soon be used to refine laws and reduce errors.
\end{abstract}

\section{Introduction}

Observers of machine learning and law focus on issues of regulation. The nascent literature has investigated how humans can best regulate artificially intelligent machines in order to ensure that new technologies avoid unintended deleterious consequences, such as relying inappropriately on imperfect automated systems or introducing unanticipated biases into decision-making processes (see, e.g., National Science \& Technology Council 2016). Commentators have explored questions such as: How should we regulate self-driving vehicles and automated aircraft? (Surden \& Williams 2016) How do we ensure the fairness and non-discriminatory nature of automated programs used in banking, insurance, and the justice system? (Barocas \& Selbst 2016) And how do we deal with the privacy issues that arise from the use of big data and potential inequality concerns that emerge as a consequence of automated services? (Hartzog et al 2015; Joh 2014, 2016; O’Neil 2016.)

In this article, we take a different approach. Rather than focusing on how human-created laws should regulate machines, we explore how machine-learning technology can improve regulation of human behavior. Traditional scholars of regulation have for decades been exposing the limitations of the modern regulatory state and proposing various means of improving upon the shortcomings of the 20th century approach to regulation in major market economies. In our view, a machine-aided, data-centric approach may substantially curtail many of these traditional limitations of regulation. It represents a novel and promising approach to regulation that has been under-appreciated thus far in the literature. 
We foresee two broad applications of machine learning in the regulation of behavior. First, machine learning can help streamline the administration of law. Machine learning algorithms can help predict outcomes of court cases. This will allow regulators to provide faster, more consistent, and more reliable rulings. We provide an example of how machine learning can apply to the regulation of tax laws.

Second, machine-learning algorithms can become the law. Machine learning can be used to not only reflect the law, but also to refine and improve the law. Machine learning algorithms can predict consequences of human behavior. This will facilitate the development of laws that are context-specific, tailored to every possible scenario. Such advances will fundamentally change the structure of law. In light of this added predictive power, some human activities that are currently governed by ex post litigation will be governed by ex ante regulation. Machine learning will thus be used to refine the law and reduce errors. We provide an example of how machine-learning tools may change the way laws deal with medical malpractice law.

We do not propose that machine learning can solve all regulatory problems. Nor do we suggest that technology will iron out all deficiencies in the law. Further, we recognize that the use of such technology may raise additional concerns, such as privacy and entrenchment of pre-existing biases. Questions of ethics, privacy, and autonomy persist (see, e.g, Hartzog et al 2015, Casey \& Niblett 2017). We contend, however, that machine learning can improve the regulatory state.

The paper proceeds as follows. In Section 2, we explore how machine learning tools can improve the administration of law, focusing on tax law. In Section 3, we explore how machine-learning algorithms will become the law and can be used to improve and refine the law. A final section concludes.

\section{How machine learning can improve the administration of law}

In this section, we discuss how machine learning tools can be used by regulators to improve the administration of law. We start by outlining some general problems of human-led regulation. We then turn to a specific example of a tax regulator. We outline how machine learning can better predict how courts will interpret the law in future cases.

\subsection{Some problems with human-led regulation}

Under the Pigouvian theory of regulation, government intervention is required when markets fail, perhaps due to monopoly or externalities (Pigou 1920; Stiglitz 1989). But some economists, political scientists, and legal scholars question the benefits of regulation 11 Even where government regulation is seen as necessary, the administration of law by government agencies may be frustrated by resource constraints or incompetence (McAllister 2012). In some instances, the regulator may lack the resources or expertise to enforce policy as intended.

Prediction is an important skill for regulators. One significant aspect of regulation is predicting how a court will enforce the law. A government agency often has considerable discretion in making administrative decisions, but will wish to act in a manner consistent with the court's interpretation of the law. Agencies incur a cost when they are overturned by judges, both in terms of litigation expenses and in terms of eroding the legitimacy of administrative decisions.

Resource-constrained rgulators who can accurately forecast how courts will interpret vague standards help citizens overcome legal uncertainty and comply with the law. A strong understanding of how cases will play out in court allows the regulator to allocate scarce resources toward cases that are worth pursuing and away from those battles that will be lost. But such prediction and judgment of legal outcomes by humans can often come down to educated hunches, rules of thumb, intuition, and heuristics. There is a large literature illustrating how formal, algorithmic methods of predictions consistently outperform humans in predicting outcomes across several settings (see, e.g., Grove \&

\footnotetext{
${ }^{1}$ For example, scholars have noted that many of the putative benefits regulation provides may actually be solved by simply using contracts or other forms of private ordering (Ellickson 1991; Bernstein 1992). In cases where markets or norms do not solve the problem, it has been argued that well-functioning and impartial courts can address conflicts and enforce property rights better than regulators (Coase 1960; Posner 1972). But even then, problems persist. Government regulators may be "captured" or corrupt (Becker 1983; Posner 1974). Organized interests can often achieve their own objectives through government policy at the expense of the public interest (Livermore \& Revesz 2012).
} 
Meehl 1996). Indeed, machine learning algorithms are already outperforming humans in the task of accurately predicting court decisions (see, e.g., Katz, Bommarito \& Blackman 2014).

\subsection{Example: Using machine learning in the administration of tax law}

Consider the example of tax law. There is a clear public good in citizens being aware of their legal rights and responsibilities with regards to tax. But tax law is dense, complex, and often based on vague standards. Enforcing these laws at the agency level requires tax regulators to have a strong understanding of how a court would interpret such standards. Even within the same regulatory authority, different agents, auditors, and lawyers may differ in their answers to these questions. It was recently announced, for example, that the tax regulator's call centre in Canada routinely dispensed misleading and inconsistent answers. As many as one in four queries were answered incorrectly (CBC 2015). In the United States, recent cuts to the Internal Revenue Service budget resulted in a reduced rate of audit (Nessa et al 2016). A resource-constrained tax authority will fail to adequately regulate the behavior of its citizens. This opens the possibility of undermining tax morale and fostering under-compliance.

We foresee regulators in the future using machine-driven algorithms to help inform citizens of their legal rights and responsibilities. Even if a machine-driven algorithm were only marginally more accurate than that of a human regulator, there is a clear public good from the tax regulator being able to dispense speedy, consistent, and reliable advice.

Imagine an Uber driver wishes to know whether, for tax purposes, she is an employee or a contractor. This is a fundamental question in tax law. The implications of this question can be enormous, especially in the types of deductions that can be claimed and entitlements to benefits, pensions, and insurance.

But the distinction between independent contractor and employee is not governed by a clear rule. There is no one dispositive fact that courts can look to resolve the question. The law is governed by a vague judicially-created standard called the "total relationship" test. Courts look at the relationship between the hirer and the worker and weigh up different factors. This is a classic grey area question of law. The answer is context-specific. Courts look to a number of factors including the level of control imposed by the hirer on the worker, who owns the tools and equipment that the worker needs to complete the work, the chance of profit and the risk of loss for the worker, and the level of integration of the worker into the hirer's business.

It can be difficult for taxpayers to understand their legal rights and responsibilities under such laws. The law is complicated and permits great legal uncertainty. The taxpayer may ask the tax regulator for an advance tax ruling. But the time required for a response is often prolonged. Agents who work for the regulator need to research the law on this area and determine how a court would classify an Uber driver. There would be many judicial opinions addressing this question. In Canada, for example, there have been over 600 cases in the past 20 years alone. The volume of previously-decided cases can be a hurdle for regulators. It is a large amount of information to process. After several hours of researching, the agent's decision may be incorrect or inconsistent with the decisions of other agents.

The three of us have been involved in a project using machine-learning techniques to predict how a court would likely answer this legal question (Alarie, Niblett \& Yoon 2016). We use the universe of over 600 cases decided by the Tax Court of Canada to generate the backbone of our dataset. We analyze and code each case, extracting key information in the form of relevant variables. In the process, we turn the unstructured data of judicial opinions into structured data. We use other information provided in the written opinions to generate more data. We use a neural network to create a predictive algorithm. The neural network finds hidden connections between the variables that we likely would not have specified using more traditional statistical techniques. In out-of-sample testing, more than 90 percent of predictions were found to be correct.

We predict that regulators will use algorithms similar to this one in the near future. Let's return to the example of the Uber driver. The Uber driver can ask the tax regulator whether they are an employee or a contractor. Instead of spending hours researching the law and finding relevant precedents, the regulator can simply use a system such as the one described above to answer the question with greater accuracy and confidence. Further, the machine-driven algorithm can do in minutes what currently takes hours for a human. Here, compliance advice can be instantaneously issued from the government regulator to the regulated citizen. 


\section{How machine-driven algorithms can become the law}

In this section, we describe how machine-driven algorithms can eventually become the law. Indeed, as Justice Oliver Wendell Holmes of the United States Supreme Court once famously remarked: "prophecies of what the courts will do in fact ... are what I mean by the law" (Holmes 1897, at 460-1). We describe the likely evolution toward this equilibrium. We also explain how machine learning tools can be used to not only reflect the current state of the law, but also used to improve the law.

\subsection{How machine learning can reflect the law}

The use of machine learning algorithms to predict legal decisions will lead to regulation by machine. The machine learning algorithms will mirror the law and provide instant communication on how to comply with the law. But the change from human-led regulation to machine-led regulation will not happen overnight.

At first, human regulators will merely use these predictive programs to see how judges have resolved such questions in the past. These programs would provide the regulator with a likely prediction of what might happen if a regulatory decision were to be appealed and a court were to rule on the case. This technology will allow the regulator to process questions asked of them by taxpayers with greater efficiency and speed. As the regulator becomes more confident in the accuracy and reliability of the automated responses, especially where the taxpayer's circumstances are relatively common, the entire process will become automated.

Indeed, much of this type of regulation can be done without human involvement. One could imagine programs where users enter information and are given, in essence, an advance regulatory ruling within seconds. In a world where taxpayers receive instantaneous rulings from regulators, the algorithm is the law. This new form of law is characterized by greater consistency than regulators and courts could previously offer ${ }^{2}$ The biases of regulators, adjudicators, and judges are washed away, further reducing legal uncertainty.

\subsection{How machine learning can refine the law}

In recent work, Anthony Casey and Anthony Niblett argue that machine learning technology will soon be used to refine the law. Gaps in the law can be filled by machine learning algorithms 3 Predictive algorithms will form the backbone of precise and finely calibrated laws. These laws will be tailored to individuals' circumstances and communicated directly to citizens. In this vision of the future, law will exist in a catalogue of precisely tailored directives, specifying exactly what is permissible in every unique situation. A citizen simply follows a directive optimized for her situation. Casey and Niblett refer to this new form of law as "micro-directives" (Casey \& Niblett 2017). These micro-directives will update automatically as circumstances or the objectives of the law change.

These laws improve upon the current legal framework of rules and standards. The technology will generate a decline in the use of vague standards. As described above, technology can improve upon vague standards by alleviating the uncertainty and informing citizens how to comply with objectively stated laws. The technology will also lead to the decline in the use of broad rules. While clear, rules in this form tend to be too static and rigid. At the same time, they are both over- and under-inclusive. Rules can be improved upon by taking into account particular circumstances of a case.

The result will be a new form of law that is a hybrid of rule and standard. The lawmaker can set a broad objective, which might look like a standard. But the predictive technology will take the standard and engineer a vast catalog of context-specific rules for every scenario. The evolution toward micro-directives and refined laws will be incremental. The speed of the change will be highly contextual. It will depend on the type of law. We predict that commercial fields such as tax, corporate law, securities, and antitrust will be the fastest to evolve as the cost pressure to automate laws is likely strongest in these areas and data is readily available.

\footnotetext{
${ }^{2}$ See, e.g., Niblett (2013) on judicial inconsistency.

${ }^{3}$ The three of us hold different views as to the degree to which machine learning will replace human activity in law. For example, Ben Alarie predicts that this evolution will lead to "the legal singularity" (Alarie 2016). Under this vision, law becomes completely specified, where all the gaps in law are addressed. At bare minimum though, each of us recognizes that the change is real and it is coming.
} 
The technology will generate a fundamental shift in the way that we, as a society, choose to regulate behavior. Such machine-driven algorithms will elevate the administrative state as government resolves more disputes at the regulatory rather than judicial stage. The lawmaking roles of judges will change along with the fundamental nature of law. Judges will lose much of their oversight and lawmaking power.

Readers may be concerned that regulation by machine is too static and rigid. The argument suggests that because the law will largely be based on previous judicial decisions, the room for change and adapting to new circumstances is limited; the law may not take in account new information fast enough. The use of technology here changes the nature of the evolutionary game between lawmakers and citizens (Roithmayr, Isakov \& Rand 2015). We discuss ways to allay this concern in the next section.

\subsection{How machine learning can reduce errors in the law}

In the tax example above, we showed how prior decisions of courts can be used to predict the outcomes of new hypothetical cases. The data on how courts behave can be used to generate an algorithm that can streamline regulatory behavior. The algorithm, once used by regulators and regulated parties, eventually becomes the law. But predictive technology can go further than simply telling us what the law is. It can also be used to inform us what the law should be.

Machine learning algorithms can help reduce the errors in the law. Casey and Niblett illustrate this point with the example of regulating medical malpractice (Casey \& Niblett 2017). In many jurisdictions, judges and juries currently determine whether or not a doctor has committed medical malpractice. The law is governed by a vague standard of whether the doctor deviated from a "reasonable standard of care." Doctors rely on their own experience to determine what is reasonable in a given situation.

But machine learning technology that accurately predicts consequences of likely actions will form the backbone of new medical malpractice laws. These laws will take the form of ex ante regulation, rather than ex post litigation. At first, the predictive algorithms will be merely be used to provide doctors with information superior to what they currently possess. These predictive algorithms can outline the likelihood of adverse outcomes associated with particular actions, offering warnings for conduct associated with high risk. Beyond merely providing information about the likely consequences, the machine can recommend how best to proceed. The doctor may initially be afforded the discretion to ignore these recommendations.

As the algorithms becomes increasingly accurate, the predictive algorithm will become the law. Doctors who ignore or neglect the advice of the algorithm will be found liable for medical malpractice. Those who follow the advice will likely be absolved. In the same way that doctors will likely be found negligent for failing to order an $\mathrm{x}$-ray if a patient presents with symptoms consistent with a broken limb, doctors will similarly be found negligent for ignoring the advice generated by the algorithm, or failing to consult the machine in the first place. The law of medical malpractice will begin to mirror the contours of the predictive machine-driven algorithms. This law updates instantaneously as the predictive power of the machine learning algorithm continues to learn and improve. The law of medical malpractice will become regulation by machine.

A similar dynamic will cause rapid adoption of algorithmic tools in the delivery of legal advice. No lawyer will want to disperse advice by "shooting from the hip," especially if it means that they have an increased probability of being found liable for negligence if they are wrong $4^{4}$

\section{Conclusion}

The bulk of the existing literature exploring machine learning and law has focused on the important questions of regulating the creation and use of automated machines. But machine learning tools can also be used to better regulate human behavior. In this contribution we have discussed recent research in this sphere. Regulators - plagued by problems of resource constraints, the scarcity of human capital, and inconsistency - can use machine learning tools to provide faster advice and rulings to

\footnotetext{
${ }^{4}$ Another strand of the literature has explored the effect of machine learning on the legal services industry. See, e.g., Katz (2013); Surden (2014); Susskind \& Susskind (2016); Yoon (2016).
} 
citizens. Machine learning tools can be also used to refine and improve laws, making them more applicable and relevant to the circumstances faced by citizens. Indeed, in the future, we may come to puzzle about how it came to be that 20th century regulation in an algorithmically limited environment was ever supposed to have worked at all.

\section{References}

[1] Alarie, B. (2016). The Path of the Law: Toward Legal Singularity. University of Toronto Law Journal 66(4):443-445.

[2] Alarie, B., Niblett, A., \& Yoon, A.H. (2016). Using Machine Learning to Predict Outcomes in Tax Law. Canadian Business Law Journal 58(3):231-254.

[3] Baracos, S. \& Selbst, A. (2016). Big Data's Disparate Impact. California Law Review 104(3):671-732.

[4] Becker, G.S. (1983). A Theory of Competition Among Pressure Groups for Political Influence. Quarterly Journal of Economics 98(3):371-400.

[5] Bernstein, L. (1992). Opting Out of the Legal System: Extralegal Contractual Relations in the Diamond Industry. Journal of Legal Studies 21(1):115-157.

[6] Canadian Broadcasting Corporation (CBC) (2015). Revenue Canada's call centres giving bad tax advice: report (February 8, 2015). Available at: http://www.cbc.ca/ news/politics/revenue-canada-scall-centres-giving-bad-tax-advice-report-1.2946998

[7] Casey, A.J. \& Niblett, A. (2016). Self-Driving Laws. University of Toronto Law Journal 66(4):429-442.

[8] Casey, A.J. \& Niblett, A. (2017). The Death of Rules and Standards. Indiana Law Review 92(5):forthcoming.

[9] Coase, R.H. (1960). The Problem of Social Cost. Journal of Law \& Economics 3:1-44.

[10] Ellickson, R.C. (1991). Order Without Law: How Neighbors Settle Disputes. Cambridge, Mass: Harvard University Press.

[11] Grove, W.M. \& Meehl, P.E. (1996). Comparative Efficiency of Informal (Subjective, Impressionistic) and Formal (Mechanical, Algorithmic) Prediction Procedures: The Clinical-Statistical Controversy. Psychology, Public Policy, \& Law 2(2):293-323.

[12] Hartzog, W., Conti, G., Nelson, J., \& Shay, L.A. (2015). Inefficiently Automated Law Enforcement. Michigan State Law Review 2015(5):1763-1796.

[13] Holmes, O.W. (1897). The Path of the Law. Harvard Law Review 10(8):457-478.

[14] Joh, E. (2014). Policing by Numbers: Big Data and the Fourth Amendment. Washington Law Review 89(1):35-68.

[15] Joh, E. (2016). The New Surveillance Discretion: Automated Suspicion, Big Data, and Policing. Harvard Law \& Policy Review 10(1):15-42.

[16] Katz, D.M. (2013). Quantitative Legal Prediction - Or - How I Learned to Stop Worrying and Start Preparing for the Data-Driven Future of the Legal Services Industry. Emory Law Journal 62(4):909-967.

[17] Katz, D.M., Bommarito, M. \& Blackman, J. (2014). Predicting the Behavior of the United States Supreme Court: Toward a General Approach. Available online at SSRN.

[18] Livermore, M.A. \& Revesz, R.L. (2012). Regulatory Review, Capture, and Agency Inaction. Georgetown Law Journal 101(5):1337-1398.

[19] National Science and Technology Council. (2016). Preparing for the Future of Artificial Intelligence. Available online.

[20] Nessa, M., Schwab, C., Stomberg, B., \& Towery, E. How do IRS resources affect the tax enforcement process? University of Georgia Working Paper: Mimeo. 
[21] Niblett, A. (2013). Tracking Inconsistent Judicial Behavior. International Review of Law \& Economics 34:9-20.

[22] O'Neil, C. (2016). Weapons of Math Destruction: How Big Data Increases Inequality and Threatens Democracy. London: Penguin Books.

[23] Pigou, A.C. (1920). The Economics of Welfare. London: Macmillan.

[24] Posner, R.A. (1972). A Theory of Negligence. Journal of Legal Studies 1(1):29-96.

[25] Posner, R.A. (1974). Theories of Economic Regulation, Bell Journal of Economics \& Management Science 3(5):335-358.

[26] Roithmayr, D., Isakov, A., \& Rand, D. (2015). Should Law Keep Pace with Society? Relative Update Rates Determine the Co-Evolution of Institutional Punishment and Citizen Contributions to Public Goods. Games 6:124-149.

[27] Stiglitz, J. (1989). Markets, Market Failure, and Development. American Economic Review: Papers and Proceedings 79(2):197-203.

[28] Surden, H. (2014). Machine Learning and Law. Washington Law Review 89(1):87-115.

[29] Surden, H. \& Williams, M. (2016). Technological Opacity, Predictability, and Self-Driving Cars. Cardozo Law Review 38:forthcoming.

[30] Susskind, R. \& Susskind, D. (2016). The Future of Professions: How Technology Will Transform the Work of Human Experts. London: Oxford University Press.

[31] Yoon, A.H. (2016). The Post-Modern Lawyer: Technology and the Democratization of Legal Representation. University of Toronto Law Journal 66(4):458-471. 